\title{
Molecular phylogeny of the Kosciuscola grasshoppers endemic to the Australian alpine and montane regions
}

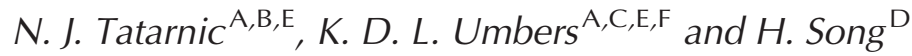 \\ A Department of Biological Sciences, Macquarie University, Sydney, NSW 2109, Australia. \\ ${ }^{B}$ Evolution \& Ecology Research Centre, University of New South Wales, Sydney, NSW 2052, Australia. \\ ${ }^{C}$ Research School of Biology, Australian National University, Canberra, ACT 0200, Australia. \\ DDepartment of Biology, University of Central Florida, Orlando, Florida 32816-2368, USA. \\ EThese authors contributed equally to this study. \\ FCorresponding author. Email: kate.umbers@mq.edu.au
}

\begin{abstract}
Diversity and speciation in Australia's alpine biota are poorly understood. Here we present a molecular phylogeny of the Australian alpine grasshopper genus Kosciuscola (Sjösted) that currently includes five described species. These grasshoppers are of interest not only because of their alpine distribution but also for the extraordinary colour change exhibited by the species $K$. tristis, whose males turn turquoise when their body temperature exceeds $25^{\circ} \mathrm{C}$. We reconstructed the phylogeny with two fragments of the mitochondrial genome using parsimony, maximum likelihood and Bayesian analyses and our data support the current taxonomy. Further, our data show little geographic structuring within some clades, which is puzzling since members of Kosciuscola are brachypterous. Finally, our data coupled with our observations on colouration provide evidence for a genetically distinct clade of $K$. tristis in the Victorian Alps. This is among the first molecular studies of an alpine invertebrate and one of a few on non-endangered, widespread Australian alpine species. More phylogenetic studies in the Australian Alps are required if we are to understand the evolution of alpine fauna and establish baseline data to monitor their response to climate change.
\end{abstract}

Received 13 September 2012, accepted 20 March 2013, published online 25 June 2013

\section{Introduction}

The alpine region in the south-east of the Australian continent harbours many endemic species. Approximately the size of Hawai'i $\left(11500 \mathrm{~km}^{2}\right)$, the Australian Alps have a limited altitudinal range of $1600-2228 \mathrm{~m}$ on the mainland and $750-1614 \mathrm{~m}$ in Tasmania. During the Pliocene (2.5 to 5 mya), rapid cooling and drying promoted the proliferation of coldadapted vegetation throughout the region (Gallagher et al. 2003; Dubey et al. 2010). The following glacial and interglacial periods that dominated the Pleistocene probably led to range expansion and contraction for many species and it is unlikely that today's species assemblage persisted through that period (Gallagher et al. 2003). By the end of the Pleistocene the current assemblage of flora and fauna became established. Today and under future climate scenarios, the flora and fauna of the alpine region are highly vulnerable to global warming (Hennessy et al. 2007). Australian mountain peaks are relatively short and isolated, so opportunities for migration southward or to higher altitudes are extremely limited (Green and Osborne 1994; Hennessy et al. 2007). It is therefore critical and urgent that we understand the current status of Alpine biodiversity and what processes have shaped today's biotic alpine assemblage, if we are to manage them effectively under future climate conditions.
Members of the grasshopper genus Kosciuscola (Sjöstedt) (Orthoptera:Acrididae: Oxyinae) are found throughout the alpine regions of Australia (Rehn 1957). This genus belongs to the small Australian endemic tribe Praxibulini, which includes four brachypterous genera whose distributions are limited to the eastern portion of the continent. The phylogenetic position of the Praxibulini within the Oxyinae is unclear because there is no other tribe that shows close morphological affinity to this tribe (Hollis 1975). The subfamily as a whole is widely distributed in the Indo-Pacific, and across Asia and Africa. Although a formal phylogenetic analysis has not yet been performed, there is little doubt that Praxibulini constitutes a monophyletic group, as it is supported by numerous morphological characters (Rehn 1957). Currently, five species within Kosciusola are recognised, one of which has two subspecies: K. cuneatus (Rehn), K. cognatus (Rehn), K. tasmanicus (Rehn), K. usitatus (Sjöstedt), K. tristis tristis (Rehn), and $K$. tristis restrictus (Rehn).

From the highest altitude $(2228 \mathrm{~m}$ ) to $1500 \mathrm{~m}$ on the mainland and up to $\sim 700 \mathrm{~m}$ in Tasmania (Key 1970), the distribution of Kosciuscola extends from the Brindabella Ranges in the north (west of Canberra), through Australia's highest peak, Mt Kosciuszko, in New South Wales (NSW) and the Victorian Alps into Tasmania's alpine region (Rehn 1957). Today, $K$. tristis populations in the high country of far south NSW are 
likely to be geographically isolated from those in northern Victoria, but probably historically shared a contiguous habitat with their Victorian counterparts (Rehn 1957). Kosciuscola tristis tristis is thought to occur across the NSW and Victorian main ranges, while the isolated alpine peak of Mt Buffalo in Victoria harbours K. tristis restrictus (Rehn 1957). Kosciuscola cognatus, the most widely distributed species in the genus, occurs from the NSW main range to the coastal plateau, and east into the Gourock ranges. Kosciuscola tasmanicus has been recorded only in the highlands of Tasmania from a restricted survey, but its range probably extends westward into the Tasmanian Alps proper. Kosciuscola usitatus is widely distributed across the Kosciuszko massif and NSW Alps. Kosciuscola cuneatus is found throughout the montane regions of the ACT, NSW and Victoria, and is absent from the highest peaks of Kosciuszko National Park.

The evolutionary relationships of Kosciuscola are of interest for several reasons. First, Australian grasshoppers are poorly understood and have received little phylogenetic and taxonomic treatment in recent years (Song 2010). With over 90\% endemism in Australian grasshopper genera (Key 1992), there appears to have been a substantial Australian radiation of Acrididae, yet this has not translated into a corresponding degree of taxonomic research (Song 2010). Second, Kosciuscola are a truly alpine group in an otherwise dry, hot and flat continent. They therefore provide an opportunity for understanding distribution patterns, population structure and reproductive isolation among sky islands (patches of high altitude habitat interspersed by low altitude valleys) in the Australian Alps. Third, Kosciuscola grasshoppers exhibit temperaturecontrolled colour change - an unusual trait among insects (O'Farrell 1964; Veron et al. 1974; Berthold 1980; Tichy and Loftus 1987). Colour change is most striking in $K$. tristis males, who turn turquoise (from almost black) when the temperature exceeds $25^{\circ} \mathrm{C}$ (Key and Day $1954 a$; Key and Day $1954 b$; Umbers 2011; Umbers et al. 2013a, 2013b). The evolution of their colour-change capacity, unique among grasshoppers, makes them a fascinating subject for evolutionary study. In this study we reconstruct a phylogeny of Kosciuscola using molecular data to determine the phylogenetic relationships among the Kosciuscola species.

\section{Materials and methods}

\section{Sampling and identification}

Kosciuscola grasshoppers were collected from 34 sites across south-eastern NSW, north-eastern Victoria and central Tasmania in the summers of 2007 through 2011 (Table 1, Fig. 1). Collection sites were determined using locality records obtained from the Kosciuscola collection at the Australian National Insect Collection (CSIRO, Canberra). To distinguish Kosciuscola from other genera, we compared our samples with museum paratype specimens and consulted the generic key of Rehn (1957). Salient characters include eye colour and size, brachypterous wing morphology, the presence of cheek patterning, and overall body shape. In the field, Kosciuscola grasshoppers were identified to species level with reference to the field identification key of Green and Osborne (1994; table 9.1, p. 171). Upon collection, grasshoppers were placed in a freezer at around $-20^{\circ} \mathrm{C}$ overnight and then stored in $70 \%$ ethanol at $4{ }^{\circ} \mathrm{C}$ until processing. To ensure our identifications were accurate to species we posted a representative assortment of exemplars to Dr David C. F. Rentz, Australia's authority on Orthoptera, who confirmed our initial identifications. Additionally, identifications for all specimens used in this analysis were rechecked against the type specimens housed in the Australian National Insect Collection, CSIRO, Canberra.

\section{DNA extraction, amplification and sequencing}

Total genomic DNA was extracted from muscle tissue attaching the hind femora to the metathorax using a saltingout protocol adapted from Sunnucks and Hales (1996). Mitochondrial cytochrome $c$ oxidase subunit I (COI) and cytochrome $c$ oxidase subunit II (COII) were selected, as these loci are known to be informative in insect systematics. Many orthopteran insects are known to have fragments of mitochondrial DNA that have been integrated into the nuclear genome, known as nuclear mitochondrial pseudogenes (numts), which potentially lead to difficulties in generating orthologous mitochondrial sequence data (Sword et al. 2007; Song et al. 2008; Moulton et al. 2010). To avoid numt coamplification contamination, a long-range polymerase chain reaction (PCR) was performed followed by nested PCR based on the recommendation outlined by Song et al. (2008). For the initial long-range PCR, the primers OR-MetJ (F - 5-CATAAGCTAA TGGGTTCATAC-3) and Rlys (5-GAGACCAGTACTTG CTTTCAGTCATC-3), which target tRNA-Met and tRNA-Lys, respectively, were used to amplify a $3630 \mathrm{bp}$ fragment that includes several genes located between these two tRNAs. We used the DNA polymerase Elongase (Invitrogen) for the longrange PCR. Reactions comprised a 1:4 ratio of Buffers A and B respectively, $125 \mu \mathrm{M}$ of each $\mathrm{dNTP}, 1 \mu \mathrm{L}$ Taq and $2.0 \mu \mathrm{M}$ of each primer in a final volume of $25 \mu \mathrm{L}$. Reaction conditions were an initial denaturation at $92^{\circ} \mathrm{C}$ for $2 \mathrm{~min}$, and 40 cycles of $92^{\circ} \mathrm{C}$ for $30 \mathrm{~s}, 50^{\circ} \mathrm{C}$ for $30 \mathrm{~s}, 60^{\circ} \mathrm{C}$ for $5 \mathrm{~min}$, and a final extension at $60^{\circ} \mathrm{C}$ for $20 \mathrm{~min}$. A $1: 10$ dilution for each long-range PCR product was prepared as a template for the nested PCR to amplify COI and COII genes using the primer pairs, TW-J1301 (5-GTTAAWTAAACTAATARCCTTCAAA-3) and mtd15 (5-TCATAAGTTCARTATCATTG-3), and Fleu (5-TCTAATA TGGCAGATTAGTGC-3) and Rlys (5-GAGACCAGTACTTG CTTTCAGTCATC-3), respectively. Each $25 \mu \mathrm{L}$ reaction contained $0.25 \mu \mathrm{L}$ of GoTaq ${ }^{\circledR}$ flexi DNA polymerase (Promega), $1.0 \mu \mathrm{M}$ of each primer, $200 \mu \mathrm{M}$ each dNTP, $2.0 \mathrm{mM} \mathrm{MgCl}_{2}$ in $1 \times$ Buffer final concentration. A touch-down profile comprised an initial denaturation at $94^{\circ} \mathrm{C}$ for 2 min then cycles of: denaturing at $94^{\circ} \mathrm{C}$ for $30 \mathrm{~s}$, annealing at $55^{\circ} \mathrm{C}$ to $40^{\circ} \mathrm{C}$ over 15 cycles in increments of $1^{\circ} \mathrm{C}$ per cycle for $30 \mathrm{~s}$, extension at $68^{\circ} \mathrm{C}$, then 20 cycles of $94^{\circ} \mathrm{C}$ for $30 \mathrm{~s}, 40^{\circ} \mathrm{C}$ for $30 \mathrm{~s}, 68^{\circ} \mathrm{C}$ for $2 \mathrm{~min}$ and $30 \mathrm{~s}$ and a final extension of $7 \mathrm{~min}$ at $68^{\circ} \mathrm{C}$. Products were visualised on a $2 \%$ agarose gel and samples containing a band of the expected base pair size were purified using ExoSapIt (Applied Biosystems). Purified amplicons were sequenced in the forward direction (approx $5 \mathrm{ng} \mathrm{mL}^{-1}$ ) on an ABI 3730XL sequencer (Macrogen, Korea). Sequences generated in this study were submitted to GenBank and are available under accession numbers JX827266 to JX827299 for COI and JX827322 to JX827355 for COII (Table 2). 
Table 1. Sample location data and the number of males and females from each location included in the analysis

\begin{tabular}{|c|c|c|c|c|c|c|}
\hline Species & Location & Altitude (m) & Latitude & Longitude & Males & Females \\
\hline K. cuneatus & Brindabella Ranges - Piccadilly Circus & 1255 & -35.359596 & 148.799659 & 2 & 1 \\
\hline K. cuneatus & Brindabella Ranges - Mt Aggie car park & 1408 & -35.473185 & 148.768752 & 0 & 3 \\
\hline K. cuneatus & Brown Mountain - Bombala River & 1010 & -36.558964 & 149.280238 & 1 & 2 \\
\hline K. cuneatus & Brown Mountain - Steeple Flat Rd & 1209 & -36.594193 & 149.381765 & 1 & 1 \\
\hline K. cuneatus & Tantawangalo Mountain & 804 & -36.786861 & 149.504355 & 1 & 2 \\
\hline K. cuneatus & Snowy River Way - East Jindabyne & 1160 & -36.510736 & 148.682717 & 0 & 1 \\
\hline K. cognatus & Wilson's Valley - Kosciuszko Rd & 1463 & -36.349778 & 148.521968 & 1 & 1 \\
\hline K. cognatus & Merritt's Track (Thredbo) & 1423 & -36.500013 & 148.304888 & 1 & 0 \\
\hline K. cognatus & Merritt's Track (Thredbo) & 1500 & -36.499698 & 148.301516 & 1 & 1 \\
\hline K. cognatus & Merritt's Track (Thredbo) & 1749 & -36.493428 & 148.293817 & 0 & 1 \\
\hline K. cognatus & Merritt's Track (Thredbo) & 1860 & -36.492698 & 148.290419 & 0 & 1 \\
\hline K. cognatus & Merritt's Track (Thredbo) & 1918 & -36.494035 & 148.287958 & 1 & 1 \\
\hline K.t.tristis & Falls Creek & 1723 & -36.869113 & 147.273278 & 1 & 1 \\
\hline K.t. restrictus & Mount Buffalo & 1333 & -36.733952 & 146.80591 & 0 & 1 \\
\hline K.t.tristis & Great Alpine Rd - Mount Hotham & 1792 & -36.976338 & 147.122183 & 1 & 1 \\
\hline K. t. tristis & Road to Dargo (Mt Hotham) & 1579 & -37.080653 & 147.109677 & 1 & 2 \\
\hline K.t.tristis & Dead Horse Gap (Thredbo) & 1709 & -36.517171 & 148.264549 & 1 & 0 \\
\hline K.t.tristis & Dead Horse Gap (Thredbo) & 1943 & -36.501825 & 148.272733 & 1 & 0 \\
\hline K.t. tristis & Dead Horse Gap (Thredbo) & 1944 & -36.501825 & 148.272733 & 1 & 0 \\
\hline K.t.tristis & Guthega & 1780 & -36.382975 & 148.376389 & 1 & 0 \\
\hline K.t.tristis & Merritt's Track (Thredbo) & 1669 & -36.49594 & 148.295011 & 0 & 1 \\
\hline K. usitatus & Dead Horse Gap (Thredbo) & 1790 & -36.512429 & 148.267974 & 0 & 1 \\
\hline K. usitatus & Dead Horse Gap (Thredbo) & 1900 & -36.505546 & 148.272265 & 1 & 0 \\
\hline K. usitatus & Rennix Walk - Kosciuszko Rd & 1580 & -36.361007 & 148.507906 & 1 & 0 \\
\hline K. usitatus & Perisher Valley - Kosciuszko Rd & 1749 & -36.399028 & 148.420695 & 1 & 1 \\
\hline K. usitatus & Merritt's Track (Thredbo) & 1423 & -36.500013 & 148.304888 & 0 & 1 \\
\hline K. usitatus & Merritt's Track (Thredbo) & 1749 & -36.493428 & 148.293817 & 1 & 1 \\
\hline K. usitatus & Merritt's Track (Thredbo) & 1860 & -36.492698 & 148.290419 & 0 & 2 \\
\hline K. usitatus & Merritt's Track (Thredbo) & 2027 & -36.482978 & 148.280562 & 0 & 1 \\
\hline K. tasmanicus & Waddamana - Lake Hwy & 569 & -42.1301 & 146.7487 & 1 & 2 \\
\hline K. tasmanicus & Miena - Lake Hwy & 1055 & -41.910767 & 146.0816834 & 0 & 1 \\
\hline K. tasmanicus & Vale of Belvoir - Belvoir Rd & 842 & -41.55629 & 145.93405 & 2 & 0 \\
\hline K. tasmanicus & Tarraleah & 575 & -42.294934 & 146.438467 & 2 & 1 \\
\hline K. tasmanicus & Penstock Lagoon - Lake Hwy & 913 & -42.099534 & 146.7587834 & 1 & 0 \\
\hline
\end{tabular}

\section{Phylogenetic reconstruction}

Despite using a nested PCR approach, many of the sequences still contained pseudogenes (see Results). To remove these from the dataset, we checked all sequences by eye for evidence of multiple amplification and translated all sequences to look for stop codons (Bensasson et al. 2001). All unreliable sequences were excluded. For the remaining sequences ambiguous bases were corrected using GENEIOUS (Version 2.8.5 Biomatters NZ). Sequences were aligned using the GENEIOUS Aligner implemented in the software (Cost Matrix $=65 \%$, Gap Open Penalty $=12$, Gap Extension Penalty $=3$, Iterations $=2$ ). Sequences were translated to identify the open reading frame and trimmed accordingly. The complete mitochondrial genomes of two additional grasshoppers, Oxya chinensis (NC_010219) and Locusta migratoria tibetensis (NC_015624), were retrieved from GenBank and included as outgroups.

We performed phylogenetic analyses using parsimony, maximum likelihood (ML) and Bayesian frameworks (BA). The parsimony analysis was conducted using PAUP version 4.0b10 (Swofford 2002). For ML and BA analyses, we used JModeltest (Version 0.1.1) (Posada 2008) to select the optimal nucleotide substitution model for each gene. Under the Akaike Information Criterion, the GTR $+\mathrm{G}+\mathrm{I}$ substitution model was selected for each partition. ML analysis was conducted in RAxML 7.2.8 (Stamatakis 2006), with the GTRGAMMA+I model applied to individual gene partitions. Nodal support was assessed through bootstrap replication $(n=1000)$. Bayesian analysis was conducted in MrBAYES 3.1.2 (Huelsenbeck and Ronquist 2001), with the unlinked GTR + G + I model applied to individual gene partitions using default priors. We ran four runs with four chains each for 10 million generations, sampling every 1000 generations. We plotted the likelihood trace for each run to assess convergence in Tracer 1.5.0 (Rambaut and Drummond, 2003-2009), and discarded an average of 25\% of each run as burn-in. Nodal support was assessed from posterior probabilities.

\section{Divergence dating}

No fossil record exists for Australian alpine grasshoppers or any closely related genera to calibrate internal divergence events. Instead, we used a substitution rate of $2.3 \%$ per million years to estimate species divergence times (Brower 1994; Knowles 2000; Knowles and Otte 2000). This is clearly a rough estimate, as it is unrealistic that rates of molecular evolution are universal across invertebrates (Thomas et al. 2006; Ho and Lanfear 2012; Lanfear and Ho 2012). Nevertheless, we proceeded using this method to 


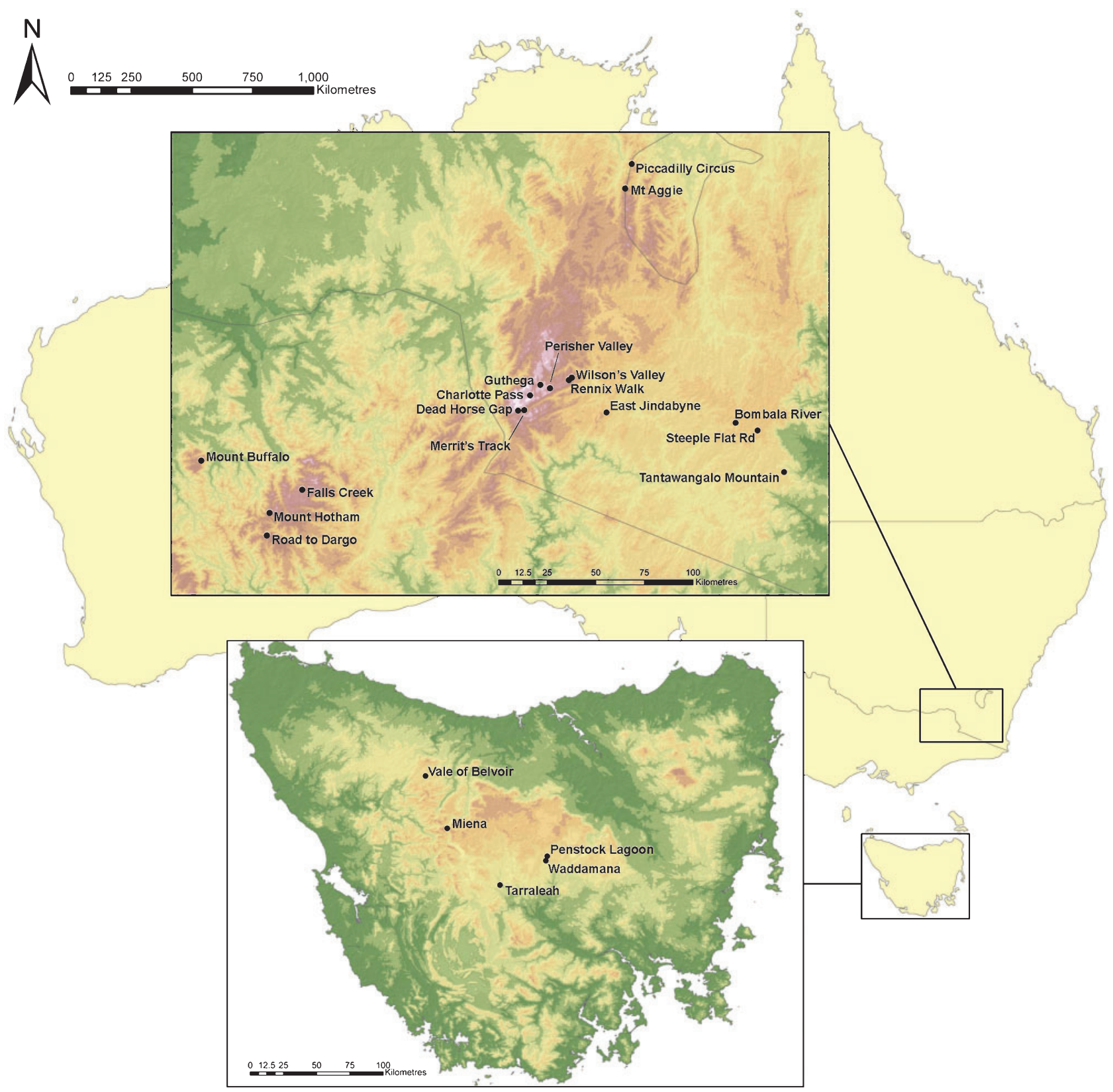

Fig. 1. Map of sampling locations across the Australian Alps National Parks in southern Australia.

allow comparison with other studies, and to gain an indication of the landscape and climate forces that may have influenced diversification patterns.

\section{Results}

\section{Amplification of $\mathrm{COI}$ and COII}

DNA was extracted from 132 grasshoppers. We successfully amplified clear, single-banded PCR product for 202 of 264 reactions (across two loci). Of the 202 successful amplifications and sequences, 163 were included in further analyses. In 57 grasshoppers, PCR and sequencing was successful for both loci and thus included in phylogenetic reconstruction

\section{Phylogenetic analyses of $\mathrm{COI}$ and COII}

Sequence alignment and editing resulted in the inclusion of 487 base pairs (bp) of COI and 669 base pairs of COII. Concatenation of COI and COII sequences produced a $1156 \mathrm{bp}$ fragment for analyses. Within the concatenated alignment, 218 sites were phylogenetically informative. All three analyses yielded very similar optimal trees thus for convenience, our discussion refers to relationships inferred by 
Table 2. GenBank accession numbers for all individuals

\begin{tabular}{|c|c|c|c|c|c|c|}
\hline Species & Location & Altitude (m) & Sex & Number & $\mathrm{COI}$ & COII \\
\hline K. tasmanicus & Penstock Lagoon & 913 & $\mathrm{~m}$ & 1 & JX827266 & JX827322 \\
\hline K. tasmanicus & Tarraleah & 575 & $\mathrm{f}$ & 1 & JX827267 & JX827323 \\
\hline K. tasmanicus & Tarraleah & 575 & $\mathrm{~m}$ & 1 & JX827268 & JX827324 \\
\hline K. tasmanicus & Tarraleah & 575 & $\mathrm{~m}$ & 2 & JX827269 & JX827325 \\
\hline K. tasmanicus & Waddamana & 569 & $\mathrm{~m}$ & 1 & JX827270 & JX827326 \\
\hline K. tasmanicus & Waddamana & 569 & $\mathrm{f}$ & 1 & JX827271 & JX827327 \\
\hline K. tasmanicus & Waddamana & 569 & $\mathrm{f}$ & 2 & JX827272 & JX827328 \\
\hline K. tasmanicus & Miena & 1055 & $\mathrm{f}$ & 1 & JX827273 & JX827329 \\
\hline K. tasmanicus & Vale of Belvoir & 842 & $\mathrm{~m}$ & 3 & JX827274 & JX827330 \\
\hline K. cognatus & Brindabella Ranges & 1255 & $\mathrm{f}$ & 1 & JX827275 & JX827331 \\
\hline K. cognatus & Brindabella Ranges & 1256 & $\mathrm{~m}$ & 1 & JX827276 & JX827332 \\
\hline K. cognatus & Brindabella Ranges & 1257 & $\mathrm{~m}$ & 2 & JX827277 & JX827333 \\
\hline K. cognatus & Brindabella Ranges & 1408 & $\mathrm{f}$ & 1 & JX827278 & JX827334 \\
\hline K. cognatus & Brindabella Ranges & 1408 & $\mathrm{f}$ & 2 & JX827279 & JX827335 \\
\hline K. cognatus & Brindabella Ranges & 1408 & $\mathrm{f}$ & 6 & JX827280 & JX827336 \\
\hline K. cognatus & Brown Mountain & 1010 & $\mathrm{f}$ & 2 & JX827281 & JX827337 \\
\hline K. cognatus & Brown Mountain & 1010 & $\mathrm{f}$ & 3 & JX827282 & JX827338 \\
\hline K. cognatus & Brown Mountain & 1010 & $\mathrm{~m}$ & 1 & JX827283 & JX827339 \\
\hline K. cognatus & Brown Mountain & 1209 & $\mathrm{f}$ & 1 & JX827284 & JX827340 \\
\hline K. cognatus & Brown Mountain & 1209 & $\mathrm{~m}$ & 2 & JX827285 & JX827341 \\
\hline K. cognatus & Snowy River Way & 804 & $\mathrm{f}$ & 2 & JX827286 & JX827342 \\
\hline K. cognatus & Snowy River Way & 804 & $\mathrm{~m}$ & 3 & JX827287 & JX827343 \\
\hline K. cognatus & Snowy River Way & 1160 & $\mathrm{f}$ & 1 & JX827288 & JX827344 \\
\hline K. cognatus & Kosciuszko Rd & 1463 & $\mathrm{f}$ & 1 & JX827289 & JX827345 \\
\hline K. cognatus & Kosciuszko Rd & 1463 & $\mathrm{~m}$ & 1 & JX827290 & JX827346 \\
\hline K. cognatus & Merritt's Trail & 1423 & $\mathrm{~m}$ & 1 & JX827291 & JX827347 \\
\hline K. cognatus & Merritt's Trail & 1500 & $\mathrm{f}$ & 1 & JX827292 & JX827348 \\
\hline K. cognatus & Merritt's Trail & 1500 & $\mathrm{~m}$ & 1 & JX827293 & JX827349 \\
\hline K. cognatus & Merritt's Trail & 1749 & $\mathrm{f}$ & 1 & JX827294 & JX827350 \\
\hline K. cognatus & Merritt's Trail & 1860 & $\mathrm{~m}$ & 1 & JX827295 & JX827351 \\
\hline K. cognatus & Merritt's Trail & 1918 & $\mathrm{f}$ & 1 & JX827296 & JX827352 \\
\hline K. cognatus & Merritt's Trail & 1918 & $\mathrm{~m}$ & 1 & JX827297 & JX827353 \\
\hline K. t. tristis & Falls Creek & 1723 & $\mathrm{f}$ & 3 & JX827298 & JX827354 \\
\hline K.t.tristis & Falls Creek & 1723 & $\mathrm{~m}$ & 1 & JX827299 & JX827355 \\
\hline K. t. restrictus & Mount Buffalo & 1333 & $\mathrm{f}$ & 2 & JX827300 & JX827356 \\
\hline K.t.tristis & Mount Hotham & 1792 & $\mathrm{f}$ & 1 & JX827301 & JX827357 \\
\hline K.t.tristis & Mount Hotham & 1792 & $\mathrm{~m}$ & 1 & JX827302 & JX827358 \\
\hline K. t. tristis & Road to Dargo & 1579 & $\mathrm{f}$ & 1 & JX827303 & JX827359 \\
\hline K.t.tristis & Road to Dargo & 1579 & $\mathrm{~m}$ & 1 & JX827304 & JX827360 \\
\hline K.t. tristis & Road to Dargo & 1579 & $\mathrm{~m}$ & 2 & JX827305 & JX827361 \\
\hline K.t. tristis & Dead Horse Gap & 1709 & $\mathrm{~m}$ & 3 & JX827306 & JX827362 \\
\hline K.t.tristis & Dead Horse Gap & 1943 & $\mathrm{~m}$ & 1 & JX827307 & JX827363 \\
\hline K. t. tristis & Dead Horse Gap & 1944 & $\mathrm{~m}$ & 19 & JX827308 & JX827364 \\
\hline K. t. tristis & Guthega & 1780 & $\mathrm{~m}$ & 3 & JX827309 & JX827365 \\
\hline K.t.tristis & Merritt's Trail & 1669 & $\mathrm{f}$ & 1 & JX827310 & JX827366 \\
\hline K. usitatus & Dead Horse Gap & 1790 & $\mathrm{f}$ & 1 & JX827311 & JX827367 \\
\hline K. usitatus & Dead Horse Gap & 1900 & $\mathrm{~m}$ & 2 & JX827312 & JX827368 \\
\hline K. usitatus & Kosciuszko Rd & 1580 & $\mathrm{~m}$ & 1 & JX827313 & JX827369 \\
\hline K. usitatus & Kosciuszko Rd & 1749 & $\mathrm{f}$ & 1 & JX827314 & JX827370 \\
\hline K. usitatus & Kosciuszko Rd & 1749 & $\mathrm{~m}$ & 1 & JX827315 & JX827371 \\
\hline K. usitatus & Merritt's Trail & 1423 & $\mathrm{f}$ & 1 & JX827316 & JX827372 \\
\hline K. usitatus & Merritt's Trail & 1749 & $\mathrm{f}$ & 1 & JX827317 & JX827373 \\
\hline K. usitatus & Merritt's Trail & 1749 & $\mathrm{~m}$ & 1 & JX827318 & JX827374 \\
\hline K. usitatus & Merritt's Trail & 1860 & $\mathrm{f}$ & 1 & JX827319 & JX827375 \\
\hline K. usitatus & Merritt's Trail & 1860 & f & 3 & JX827320 & JX827376 \\
\hline K. usitatus & Merritt's Trail & 2027 & $\mathrm{f}$ & 1 & JX827321 & JX827377 \\
\hline
\end{tabular}

the ML analysis. On the ML figure we have included posterior probabilities from our Bayesian analysis on major nodes (Fig. 2).
From the locations at which we sampled, Kosciuscola fall into five well supported clades: (cuneatus, (tristis, (usitatus, (cognatus, tasmanicus)))) (Fig. 2). Kociuscola cuneatus from 


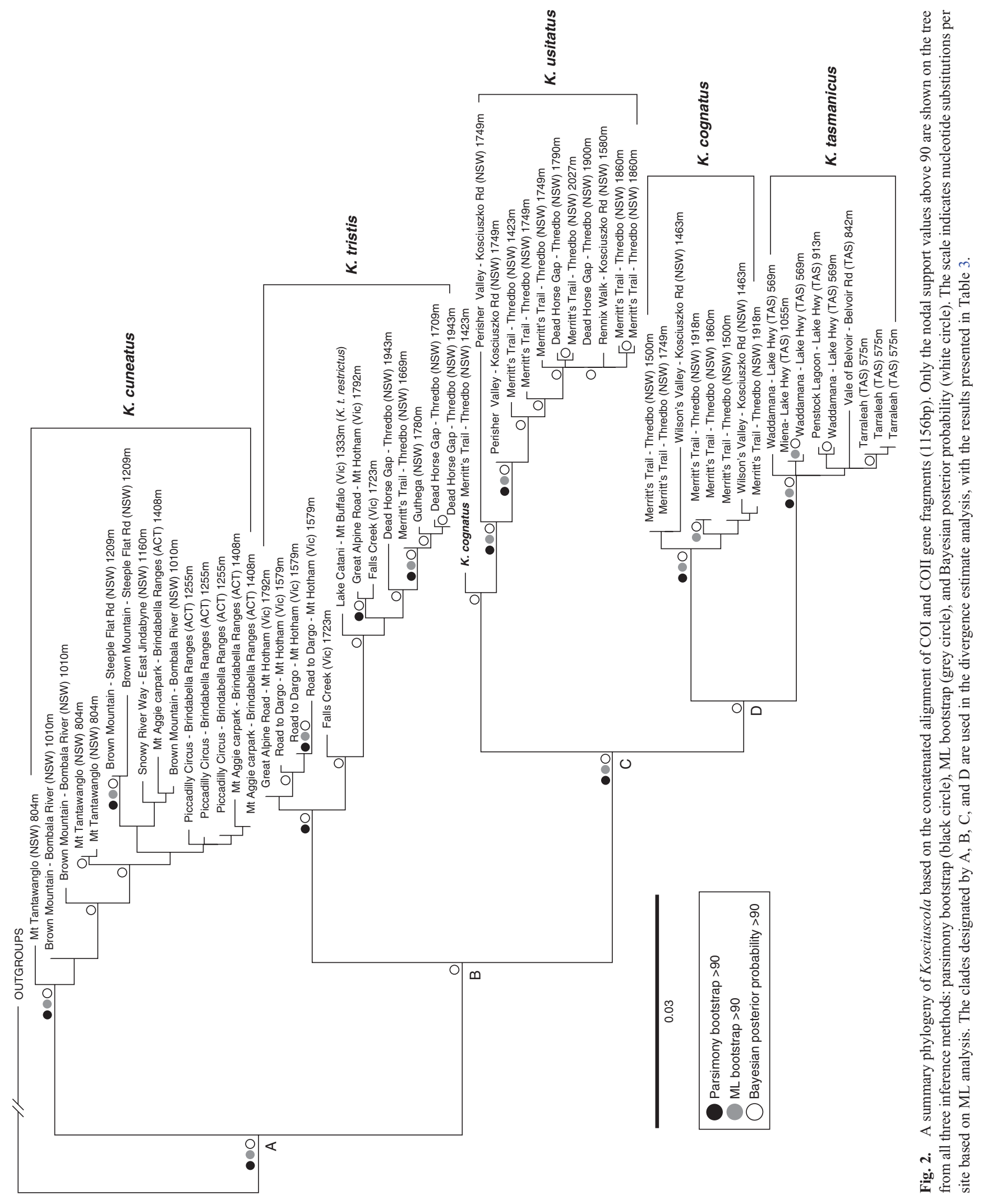


the Brindabella Ranges, Brown Mountain and Snowy River Way form a distinct group and the earliest diverging lineage within Kosciuscola. Kosciuscola cognatus forms a well resolved sister clade to K. tasmanicus, with these, in turn, sister to K. usitatus and K. tristis.

\section{Divergence dating}

Using the $2.3 \%$ per million years rate, our estimates suggest that Kosciuscola diverged from the outgroups included in our tree around 6.30 mya (range: 5.26-7.49 mya). Between the Kosciuscola species, average divergence times range from 1.87 to 3.09 mya (Table 3 ).

\section{Discussion}

Our analyses broadly support the original species delimitations in Rehn (1957). The strongly supported sister relationship between $K$. cognatus and $K$. tasmanicus suggests the ancestor to these two species may have been widely spread across the mainland and Tasmania before the land bridge joining the two closed, promoting population isolation and speciation. Interestingly, in the ML tree, one high altitude $K$. cognatus individual was grouped with $K$. usitatus. Campbell and Dearn (1980) reported morphological evidence for the existence of hybrids between $K$. cognatus and $K$. usitatus. Our data also suggest that the $K$. cognatus individual that grouped with $K$. usitatus may represent a cross between the two. While this individual is consistent with the results of Campbell and Dearn, we suggest further analysis (e.g. of nuclear markers) and specific sampling is required to confirm the presence of hybrids, and that it may be an interesting area for future population level studies.

Within K. tristis, there is no strong genetic structure despite the geographical divide. However there are two clusters, one composed entirely of individuals from the Victorian Alps, and the other composed of individuals from the Victorian Alps, the New South Wales Alps, and one specimen from the isolated alpine peak of Mount Buffalo (Victoria). The placement of the Victorian specimens in the predominantly NSW clade may support the presence of intergrades as previously suggested by Rehn (1957) in the Victorian main range between the two recognised subspecies, $K$. tristis tristis from Kosciuszko

Table 3. Genetic distances and estimated divergence times for Kosciuscola.

\begin{tabular}{lcc}
\hline Node & $\begin{array}{c}\text { Average mtDNA uncorrected } \\
\text { 'P' distance (range) }\end{array}$ & $\begin{array}{c}\text { Divergence time based on } \\
\text { 2.3\% per million years }\end{array}$ \\
\hline$A$ & $0.071(0.049-0.089)$ & $3.09(2.13-3.87)$ \\
$B$ & $0.064(0.051-0.076)$ & $2.78(2.22-3.30)$ \\
$C$ & $0.058(0.015-0.065)$ & $2.52(0.65-2.83)$ \\
$D$ & $0.043(0.036-0.053)$ & $1.87(1.57-2.30)$ \\
\hline Taxon & Within species average mtDNA \\
& uncorrected 'P' distance (range) \\
\hline K. cuneatus & $0.008(0-0.024)$ & \\
K. tristis & $0.019(0-0.042)$ & \\
K. usitatus & $0.010(0-0.035)$ & \\
K. cognatus & $0.011(0-0.031)$ & \\
K. tasmanicus & $0.005(0-0.010)$ \\
\hline
\end{tabular}

Plateau (NSW), and $K$. tristis restrictus from Mt Buffalo (Vic.) (Rehn 1957). Significantly, unlike K. t. tristis from Kosciuszko, males from these Victorian $K$. tristis samples exhibit distinct colour patterning, with a yellowed face and royal blue abdomen apex (K. D. L. Umbers, pers obs; Fig. 3). This differs significantly from the $K$. $t$. tristis habitus, where male body colour is uniformly coloured turquoise when above $25^{\circ} \mathrm{C}$ and nearblack when their body temperature is below $10^{\circ} \mathrm{C}$ (Fig. 3). Additional morphological and molecular analyses are required to more accurately determine how the $K$. tristis populations are structured.

The limited geographic structuring observed within Kosciuscola species is surprising considering Kosciuscola are flightless and semelparous, and that many of the locations sampled in this study are hundreds of kilometres apart. Lack of structuring may be the result of two conflicting possibilities: either populations undergo genetic mixing across localities or populations have become isolated too recently to be resolved using these mitochondrial loci. Kosciuscola grasshoppers have a short growing season (January to March) and a short mating season (March to May) (K. D. L. Umbers, pers. obs.). Additionally, they are brachypterous (vestigially winged), so they cannot fly and thus have limited dispersal capabilities. Also, for Kosciuscola species, ski fields, farms and areas of low altitude create formidable barriers, fragment their habitat (Chapple et al. 2005), and further limit their ability to disperse. In combination, these factors suggest the current populations do not interbreed, especially those separated by several kilometres (K. tristis from Dead Horse Gap are separated from the Guthega population by around $30 \mathrm{~km}$ ). We therefore suggest that while Kosciuscola populations living on different plateaus are reproductively isolated, they exhibit incomplete lineage sorting, having not been separated long enough for population differentiation to be detected (Maddison and Knowles 2006).

Anecdotal evidence suggests that populations of $K$. $t$. tristis were contiguous and highly abundant above the tree line across the Kosciuszko massif as recently as 60 years ago (Key and Day $1954 a, 1954 b$ ). Counter-intuitively, our observations over the last five years have shown that $K$. $t$. tristis occur at and below the tree line but are extremely rare in the alpine zone proper, perhaps seeking the shade of the snow gum canopy. Taken together, these observations could suggest that populations of Kosciuscola have recently become fragmented. Whether this possible shift in distribution is common to other alpine taxa is currently not known, but population level studies using microsatellites for example (Umbers et al. 2012), may shed more light on this question. Such distribution and population genetic data would be of great interest in documenting the response of species to climate change in the region. Using the $2.3 \%$ per million years 'invertebrate substitution rate' (Knowles 2000), our divergence dating results estimate that the major Kosciuscola lineages diverged between 1.9 and 3.1 million years ago (but see Thomas et al. 2006). This estimate corresponds with the beginning of the Pleistocene, a time of rapid climate fluctuation. In the Australian alps, the tree line shifted markedly with glacial cycles throughout the Pleistocene, repeatedly reopening niches (Green and Osborne 1994; Chapple et al. 2005) and perhaps promoting diversification. Although studies in the Australian alps are scarce, this result corresponds with patterns in other 

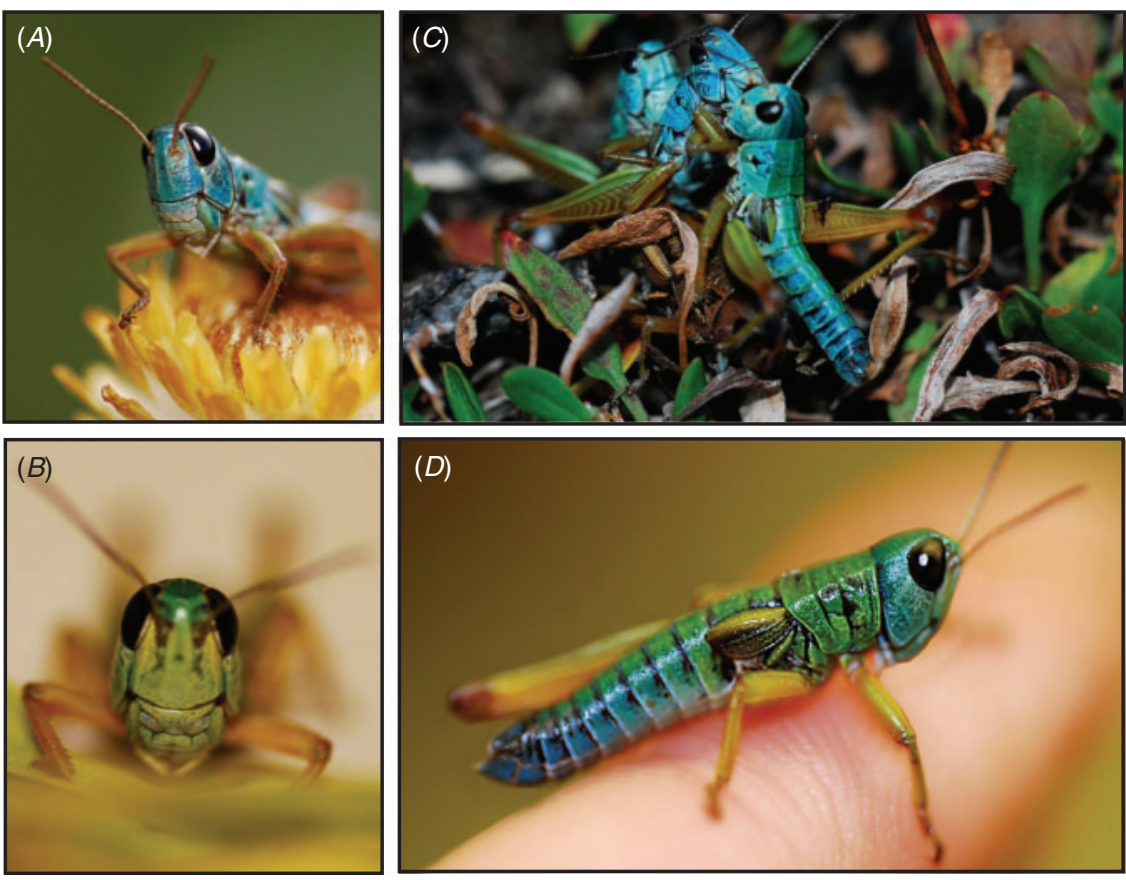

Fig. 3. Comparison of colouration of $K$. tristis' head $(A$ and $B)$ and abdomen $(C$ and $D)$ from NSW $(A$ and $C$ ) and Victoria $(B$ and $D)$.

groups so far examined (Hutchinson and Donnellan 1992; Chapple et al. 2005).

This study is the first to report on the phylogenetics of an Australian alpine invertebrate, despite the great number of charismatic species in the region (e.g. mountain katydid Acripeza reticulata, bogong moth Agritos infusa, the spotted mountain grasshopper Monistria concinna, metallic cockroach Polyzosteria viridissima (Green and Osborne 1994) and glow worm Arachnocampa buffaloensis (Baker et al. 2008)). Our results show similar broad scale patterns to phylogenies of other alpine groups such as lizards (Chapple et al. 2005; Koumoundouros et al. 2009), endangered frogs (Morgan et al. 2008) and endangered marsupials (Osborne et al. 2000; Mitrovski et al. 2007). These groups show splits between NSW and Victorian populations, which are generally attributed to the extensive passage of lowlands and the Murray River that runs west - east between the plateaus (Koumoundouros et al. 2009). In $K$. tristis, the presence of an analogous split is equivocal. The percentage sequence divergence (percentage of sites in the alignment where bases differ) between northern and southern $K$. tristis is intermediate compared with those reported for other groups. For example the percentage sequence divergence between grasshoppers from the Road to Dargo, Mt Hotham, Vic. and Dead Horse Gap, NSW is 3.3\%, compared with $4.3 \%$ for the alpine she-oak skink (Koumoundouros et al. 2009) or $1.1 \%$ for the mountain pygmy possum (Mitrovski et al. 2007). Assuming mutation rates for Australian Orthoptera are similar to those recorded in North America (Knowles 2000), we tentatively suggest that a percentage divergence of $3.3 \%$ between the northern and southern populations of $K$. tristis equates to a divergence time of around 1.4 million years ago. This coincides with the period of rapid cooling and drying in the region when the ancestral assemblage of alpine biota is thought to have developed (Green and Osborne 1994; Koumoundouros et al. 2009). Future studies on Kosciuscola should include specimens from more locations throughout the mainland and Tasmanian Alps. With these further data, estimation of divergence times through molecular clock analyses will allow the comparison of climactic oscillations of the Alps to speciation events in this group.

Phylogenetic and phylogeographic studies in the Australian Alps are rare, yet critical for understanding alpine evolution and species responses to climate change in the region. Most studies have focussed on the genetic structure of endangered species in the region (Mitrovski et al. 2007; Morgan et al. 2008). While essential to the persistence and preservation of such iconic species as the pygmy possum and corroboree frog, these studies have limited applicability to the processes governing abundant outbreeding populations and the selection pressures that have led to their current distributions. Defining phylogenies of more abundant and widely distributed groups will provide new insight into the evolution of the Australian alpine fauna and generate critical baseline data for monitoring the response of alpine ecosystems to global climate change.

\section{Acknowledgements}

The authors thank Simon Ho and Mitzy Pepper for helpful analysis advice, Czarina Manahan and Gemma Conroy for help with DNA extraction, Eliza Middleton, Leanne Battams, Felicity Evans, Ana Lopez-Llandres, Nola Umbers and Mark Umbers for assistance with collection in the field and Mitzy Pepper, Nathan Lo, Marie Herberstein, Michelle Power, Devi StuartFox, Gregory Sword, Mary Morgan-Richards and Gregory Holwell for insightful comments on earlier versions of this manuscript. We also thank Celia Symonds for generating the distribution map in Figure 1. Funding was 
provided in part by the Australian Biological Resources Survey PhD Supplement and Macquarie University Research Excellence Scholarship.

\section{References}

Baker, C. H., Graham, G. C., Scott, K. D., Cameron, S. L., Yeates, D. K., and Merritt, D. J. (2008). Distribution and phylogenetic relationships of Australian glow-worms Arachnocampa (Diptera, Keroplatidae). Molecular Phylogenetics and Evolution 48, 506-514. doi:10.1016/j.ym pev.2008.04.037

Bensasson, D., Zhang, D.-X., Hartl, D. L., and Hewitt, G. M. (2001). Mitochondrial pseudogenes: evolution's misplaced witnesses. Trends in Ecology \& Evolution 16, 314-321. doi:10.1016/S0169-5347(01) 02151-6

Berthold, G. (1980). Microtubules in the epidermal cells of Carausius morosus, their pattern and relation to pigment migration. Journal of Insect Physiology 26, 421-425. doi:10.1016/0022-1910(80)90014-1

Brower, A. V. (1994). Rapid morphological radiation and convergence among races of the butterfly Heliconius erato inferred from patterns of mitochondrial DNA evolution. Proceedings of the National Academy of Sciences of the United States of America 91, 6491-6495. doi:10.1073/ pnas.91.14.6491

Campbell, N. A., and Dearn, J. M. (1980). Altitudinal variation in and morphological divergence between three related species of grasshopper Praxibulus sp., Kosciuscola cognatus and Kosciuscola usitatus (Orthoptera: Acrididae). Australian Journal of Zoology 28, 103-118. doi: 10.1071/ZO9800103

Chapple, D. G., Keogh, J. S., and Hutchinson, M. N. (2005). Substantial genetic substructuring in southeastern and alpine Australia revealed by molecular phylogeography of the Egernia whitii (Lacertilia: Scincidae) species group. Molecular Ecology 14, 1279-1292. doi:10.1111/j.1365294X.2005.02463.x

Dubey, S., Keogh, J. S., and Shine, R. (2010). Plio-pleistocene diversification and connectivity between mainland and Tasmanian populations of Australian snakes (Drysdalia, Elapidae, Serpentes). Molecular Phylogenetics and Evolution 56, 1119-1125. doi:10.1016/j.ympev.20 10.04 .028

Gallagher, S. J., Greenwood, D. R., Taylor, D., Smith, A. J., Wallace, M. W., and Holdgate, G. R. (2003). The Pliocene climatic and environmental evolution of southeastern Australia: Evidence from the marine and terrestrial realm. Palaeogeography, Palaeoclimatology, Palaeoecology 193, 349-382. doi:10.1016/S0031-0182(03)00231-1

Green, K., Osborne, M. J. (1994). 'Wildlife of the Australian Snow-country.' (Reed Books: Sydney.)

Hennessy, K., Fitzharris, B., Bates, B. C., Harvey, N., Howden, S. M., Hughes, L., Salinger, J., and Warrick R. (2007). Australia and New Zealand. Climate Change 2007: Impacts, Adaptation and Vulnerability. Contribution of Working Group II to the Fourth Assessment Report of the Intergovernmental Panel on Climate Change. (Eds M. L. Parry, O. F. Canziani, J. P. Palutikof, P. J. van der Linden and C. E. Hanson.) pp. 507-540. (Cambridge University Press, Cambridge, UK.)

Ho, S. Y. W., and Lanfear, R. (2012). Mito-communication: callibrating mitochondrial rates in marine invertebrates. Mitochondrial DNA 23, 321. doi:10.3109/19401736.2012.683187

Hollis, D. (1975). A review of the subfamily Oxyniae (Orthoptera: Acridoidea). Bulletin of the British Museum (Natural History) Entomology 31, 189-234.

Huelsenbeck, J. P., and Ronquist, F. (2001). MRBAYEs: Bayesian inference of phylogenetic trees. Bioinformatics 17, 754-755. doi:10.1093/bioinfor matics/17.8.754

Hutchinson, M. N., and Donnellan, S. C. (1992). Taxonomy and genetic variation in the Australian lizards of the genus Pseudemoia (Scincidae: Lygosominae). Journal of Natural History 26, 215-264. doi:10.1080/ 00222939200770091
Key, K. H. L. (1970). 'Orthoptera: Grasshoppers, Locusts and Crickets.' (CSIRO Publishing: Melbourne.)

Key, K. H. L. (1992). A higher classification of the Australian Acridoidea (Orthoptera). I. General introduction and subfamily Oxyinae. Invertebrate Systematics 6, 547-551.

Key, K. H. L., and Day, M. F. (1954a). The physiological mechanism of colour change in the grasshopper, Kosciuscola tristis Sjöst. (Orthoptera: Acrididae). Australian Journal of Zoology 2, 340-363. doi:10.1071/ ZO9540340

Key, K. H. L., and Day, M. F. (1954b). A temperature-controlled physiological colour response in the grasshopper, Kosciuscola tristis Sjöst. (Orthoptera: Acrididae). Australian Journal of Zoology 2, 309-339. doi:10.1071/ZO9540309

Knowles, L. L. (2000). Tests of Pleistocene speciation in montane grasshoppers (genus Melanoplus) from the sky islands of Western North America. Evolution 54, 1337-1348.

Knowles, L. L., and Otte, D. (2000). Phylogenetic analysis of montane grasshoppers from western North America (genus Melanoplus, Acrididae: Melanoplinae). Annals of the Entomological Society of America 93, 421-431. doi:10.1603/0013-8746(2000)093[0421:PAOM $\mathrm{GF}] 2.0 . \mathrm{CO} ; 2$

Koumoundouros, T., Sumner, J., Clemann, N., and Stuart-Fox, D. (2009). Current genetic isolation and fragmentation contrasts with historical connectivity in an alpine lizard (Cyclodomorphus praealtus) threatened by climate change. Biological Conservation 142,992-1002. doi:10.1016/ j.biocon.2008.12.026

Lanfear, R., and Ho, S. Y. W. (2012). Mito-communication: mitochondrial mutation rates in the water flea Daphnia pulex. Mitochodrial DNA 23, 154doi:10.3109/19401736.2011.653806

Maddison, W. P., and Knowles, L. L. (2006). Inferring phylogeny despite incomplete lineage sorting. Systematic Biology 55, 21-30. doi:10.1080/ 10635150500354928

Mitrovski, P., Heinze, D. A., Broome, L., Hoffmann, A. A., and Weeks, A. R. (2007). High levels of variation despite genetic fragmentation in populations of the endangered mountain pygmy-possum, Burramys parvus, in alpine Australia. Molecular Ecology 16, 75-87. doi:10.11 11/j.1365-294X.2006.03125.X

Morgan, M. J., Hunter, D., Pietsch, R., Osborne, W., and Keogh, J. S. (2008). Assessment of genetic diversity in the critically endangered Australian corroboree frogs, Pseudophryne corroboree and Pseudophryne pengilleyi, identifies four evolutionarily significant units for conservation. Molecular Ecology 17, 3448-3463.

Moulton, M. J., Song, H., and Whiting, M. F. (2010). Assessing the effects of primer specificity on eliminating numt coamplification in DNA barcoding: a case study from Orthoptera (Arthropoda: Insecta). Molecular Ecology Resources 10, 615-627. doi:10.1111/j.1755-0998. 2009.02823.x

O'Farrell, A. F. (1964). On physiological colour change in some Australian Odonata. Journal of the Entomological Society of Australia (New South Wales) 1, 5-12.

Osborne, M. J., Norman, J. A., Christidis, L., and Murray, N. D. (2000). Genetic distinctness of isolated populations of an endangered marsupial, the mountain pygmy-possum, Burramys parvus. Molecular Ecology 9, 609-613. doi:10.1046/j.1365-294x.2000.00908.x

Posada, D. (2008). JModelTest: Phylogenetic model averaging. Molecular Biology and Evolution 25, 1253-1256. doi:10.1093/molbev/ msn083

Rehn, J. A. G. (1957). 'The Grasshoppers and Locusts (Acridoidea) of Australia. Family Acrididae: Subfamily Cyrtacanthacrldinae tribes Oxyini. Spathosternini. and Praxibulini.' (CSIRO: Melbourne.)

Song, H. (2010). Grasshopper systematics: past, present and future. Journal of Orthoptera Research 19, 57-68. doi:10.1665/034.019.0112

Song, H., Buhay, J. E., Whiting, M. F., and Crandall, K. A. (2008). Many species in one: DNA barcoding overestimates the number of species 
when nuclear mitochondrial pseudogenes are coamplified. Proceedings of the National Academy of Sciences of the United States of America 105, 13486-13491. doi:10.1073/pnas.0803076105

Stamatakis, A. (2006). RAxML-VI-HPC: maximum likelihood-based phylogenetic analyses with thousands of taxa and mixed models. Bioinformatics 22, 2688-2690.

Sunnucks, P., and Hales, D. F. (1996). Numerous transposed sequences of mitochondrial cytochrome oxidase I-II in aphids of the genus Sitobion (Hemiptera: Aphididae). Molecular Biology and Evolution 13, 510-524. doi:10.1093/oxfordjournals.molbev.a025612

Swofford, D. L. (2002). PAUP*. Phylogenetic Analysis Using Parsimony (*and Other Methods). Version 4. Sinauer Associates, Sunderland, MA, USA.

Sword, G. A., Senior, L. B., Gaskin, J. F., and Joern, A. (2007). Double trouble for grasshopper molecular systematics: intra-individual heterogeneity of both mitochondrial $12 \mathrm{~S}$-valine-16S and nuclear internal transcribed spacer ribosomal DNA sequences in Hesperotettix viridis (Orthoptera: Acridae). Systematic Entomology 32, 420-428. doi:10.1111/j.1365-31 13.2007.00385.x

Thomas, J. A., Welch, J. J., Woolfit, M., and Bromham, L. (2006). There is no universal molecular clock for invertebrates, but rate variation does not scale with body size. Proceedings of the National Academy of Sciences of the United States of America 103, 7366-7371. doi:10.1073/pnas. 0510251103
Tichy, H., and Loftus, R. (1987). Response characteristics of a cold receptor in the stick insect Carausius morosus. Journal of Comparative Physiology. A, Neuroethology, Sensory, Neural, and Behavioral Physiology 160, 33-42. doi:10.1007/BF00613439

Umbers, K. D. L. (2011). Turn the temperature to turquoise: cues for colour change in the male chameleon grasshopper (Kosciuscola tristis) (Orthoptera: Acrididae). Journal of Insect Physiology 57, 1198-1204. doi:10.1016/j.jinsphys.2011.05.010

Umbers, K. D. L., Dennison, S., Manahan, C. A., Blondin, L., Pagés, C., Risterucci, A.-M., and Chapuis, M.-P. (2012). Microsatellite markers for the chameleon grasshopper (Kosciuscola tristis) (Orthoptera: Acrididae), an Australian alpine specialist. International Journal of Molecular Sciences 13, 12094-12099. doi:10.3390/ijms130912094

Umbers, K. D. L., Herberstein, M. E., and Madin, J. S. (2013a). Colour in insect thermoregulation: empirical and theoretical tests in the colourchanging grasshopper, Kosciuscola tristis. Journal of Insect Physiology 59, 81-90. doi:10.1016/j.jinsphys.2012.10.016

Umbers, K. D. L., Tatarnic, N. J., Holwell, G. I., and Herberstein, M. E. $(2013 b)$. Bright turquoise as an intraspecific signal in the chameleon grasshopper (Kosciuscola tristis). Behavioral Ecology and Sociobiology 67, 439-447. doi:10.1007/s00265-012-1464-7

Veron, J. E. N., O'Farrell, A. F., and Dixon, B. (1974). The fine structure of Odonata chromatophores. Tissue \& Cell 6, 613-626. doi:10.1016/00408166(74)90004-4 